\title{
International Journal of Advanced Biochemistry Research
}
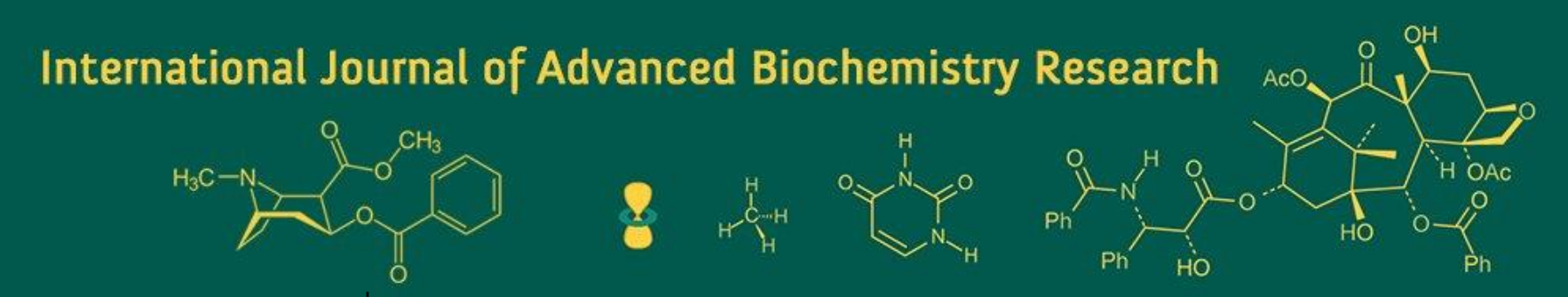

ISSN Print: $2617-4693$ ISSN Online: $2617-4707$ IJABR 2020; 4(2): 11-16 www.biochemjournal.com Received: 06-05-2020 Accepted: 20-06-2020

Sukmawati Tansil Tan Departement of DermatoVenerology, Tarumanagara University, Jakarta, Indonesia

Yohanes Firmansyah Departement of DermatoVenerology, Tarumanagara University, Jakarta, Indonesia

Jessica Elizabeth

Departement of DermatoVenerology, Tarumanagara University, Jakarta, Indonesia
Corresponding Author: Sukmawati Tansil Tan Departement of DermatoVenerology, Tarumanagara University, Jakarta, Indonesia

\section{New approach to skin burn treatment: Potential of secretome from wharton's jelly mesenchymal stem cell therapy}

\author{
Sukmawati Tansil Tan, Yohanes Firmansyah and Jessica Elizabeth
}

DOI: https://doi.org/10.33545/26174693.2020.v4.i2a.49

\section{Abstract}

Burns is a form of acute skin injury caused by trauma to heat, cold, electricity, chemicals, friction, or radiation with a high incidence rate. However, burns that are not properly treated will have an impact on further problems in the future, such as the appearance of hypertrophy scar, keloid, and contractures caused issues that have an impact on decreasing the quality of life. One of the newest methods of healing burns is using the secretome from mesenchymal stem cells. One case was reported, a 47-yearold woman with second-degree burns who was given intervention in the form of secretome from Placenta Warton Jelly Mesenchymalchymal Stem Cell (SC-PWJSC). During the 20 days of the intervention, there was excellent wound healing without hypertrophy scar or keloid with significant no local or systemic side effects were found.

Keywords: Secretom of placenta wharton jelly mesenchymal stem cell (SC-PWJSC), skin burn, hypertrophy scar, keloid

\section{Introduction}

Burns is a form of injury to the skin, or other tissues, caused by heat, cold, electricity, chemicals, friction, or radiation ${ }^{[1]}$. Most burns are caused by heat coming from hot liquids (called scalding), hot solids, or in the form of direct flames ${ }^{[2,3]}$. The incidence of burns in men and women is equal, but the underlying causes are often different. In the women's group, burns occurred as a result of using fire while cooking or from coming into contact with a cooking stove. In the male group, burns occurred due to an unsafe work environment. Lifestyle factors also influence the incidence of burns, such as smoking and alcoholism. In some cases, burns can be caused as a form of self-abuse or violence against others ${ }^{[2]}$.

Burns are a global public health problem, causing approximately 180,000 deaths each year. Burns are commonly experienced in the middle to lower-income countries. The results of world data indicate that more than two-thirds of the incidence of burns occur in Africa and Southeast Asia. The incidence rate in developed countries has decreased due to good personal safety systems, but the burn mortality rate can be very high especially in young children with an increased risk of 7 times higher, especially in lower-middle-income countries ${ }^{[2,3]}$.

Burns that are non-life-threatening (non-fatal) is a major cause of high morbidity, which in turn increases the length of hospitalization and often lead to permanent disability. Burns in the healing process often leave hypertrophy scars or keloids that are very annoying and cause permanent disability and even cause stigma in the community, which leads to rejection or expulsion. Burns are a contributor to the disability rate in the productive age group which of course causes financial losses ${ }^{[2]}$.

A report from the World Health Organization (WHO) explained that in 2004, nearly 11 million people worldwide had burns that were serious enough to require medical treatment and the risk of permanent disability ${ }^{[2,3]}$. Data reports in America reveal acute heat injuries affect nearly half a million Americans each year, leading to increased medical care costs, with approximately 40,000 hospitalizations and 3,400 deaths annually ${ }^{[4]}$. The life expectancy for burn patients is quite high, reaching $97 \%$ when handled in integrated burn treatment. Still, the problem is that integrated burn care is a minimal facility and does not exist in all places ${ }^{[5-7]}$. 
Report on the incidence of burns in developing countries with middle and lower-income, for example, in India, it is found that more than $1,000,000$ people experience moderate or severe fires every year. The Bangladesh report describes Nearly 173,000 Bangladeshi children have moderate or severe burns each year with disability rates high enough that $17 \%$ of children with burns have temporary disabilities, and $18 \%$ have permanent disabilities. The disability rate is not much different from that of Egypt, Colombia, and Pakistan $[2,3]$.

Scar tissue is a pathognomonic feature due to burns in the skin area, which has an impact on physical morbidity and psychosocial disorders for the sufferer. The most common cicatrix due to burns was hypertrophic scars with a prevalence of $70 \%{ }^{[8]}$. Frequent technological developments make the method of treating burns better with a very high life expectancy in overcoming acute problems. The problem begins in the next day because burn patients have late complications in the form of extensive scarring and contractures, itching, and pain. This whole process will interfere with physical appearance and disturbances, such as itching and loss of function over the years ${ }^{[9]}$.

Treatment of burns is generally carried out with supportive therapy, namely washing the burn with running water or normal saline, administering pain relievers both oral and topical, and administering antibiotics to prevent infection. In the case of burns that are quite dangerous, general management becomes more complex, such as giving intravenous fluids and emergency medicines when there are signs of shock ${ }^{[10-14]}$. But the reality in the field often burns cause a high rate of disability. The defect in question can be in the form of temporary or permanent disability, cosmetic disability, or loss of a limb ${ }^{[2,3]}$. Therefore, it is necessary to have a simple burn treatment mechanism that can be applied in primary health facilities but with excellent results to prevent disability rates, hypertrophy scars, or keloid.

This case report describes the potential for topical use of stem cells in burn patients in the upper limb area. The treatment of burns in these patients follows the applicable burn management protocols with the addition of stem cell treatment as an additional therapy to promote better wound healing.

\section{Case report}

The patient is a 47-year-old woman who came with a complaint of burns on her left hand as a result of being exposed to hot water from a pan that was used when cooking in the kitchen about one day ago. Current complaints are peel off skin, swollen and pain accompanied by intense burning (VAS 5/10). The patient provides relief by washing the wound with running water.

The patient is a housewife who, in her daily life, is taking care of the household and cooking in the kitchen. She has negligible medical history, such as hypertension, diabetes mellitus, heart disease, and kidney disease. The patient is also not pregnant. The patient has no history of taking routine medications.

On physical examination, she has compos mentis awareness, with moderate pain. Examination of vital signs within normal limits. Physical examination was found to be normal except for the dermatology status of the upper extremities, especially the left hand. The dermatologic state of the extremities was found in the left dorsum manus, a placardsized erythema wound $(6 \mathrm{~cm} \times 3 \mathrm{~cm})$, with a solitary amount of wet exudate around the wound (Figure 1).

The patient agreed to follow treatment using $10 \%$ gel of Secretom from Placenta Wharton Jelly Mesenchymal Stem Cell (SC-PWJSC) and control routinely every 5 days. Gel of Secretom (SC-PWJSC) was applied to the wound's surface with $0,1 \mathrm{ml} / 1 \mathrm{~cm}^{2}$, then covered with vaseline gauze and covered, then wrapped and left for 5 days. Oral antibiotic, analgetic, and vitamin $\mathrm{C}$ were also given.

Patients are also asked to note any symptoms of local side effects that may arise starting from allergic reactions such as itching, redness, burning sensation, and swelling to seeking first aid if severe side effects are alarming. Before the application is carried out, the doctor performs the action of cleaning the dead wound tissue

The patient came back for control on day 5 according to schedule. The condition of the patient's wound began to dry out, and it appeared that the granulation tissue had started to improve with clean edges (Figure 2). The patient returned to control on day 15 and day 20 with the tissue around the wound showing good growth, complete epithelialization, reduced wound size, and hyperpigmented spots. (Figure 3 and 4) The patient was delighted with the results of the therapy and without any local side effects such as allergic reactions and systemic side effects.

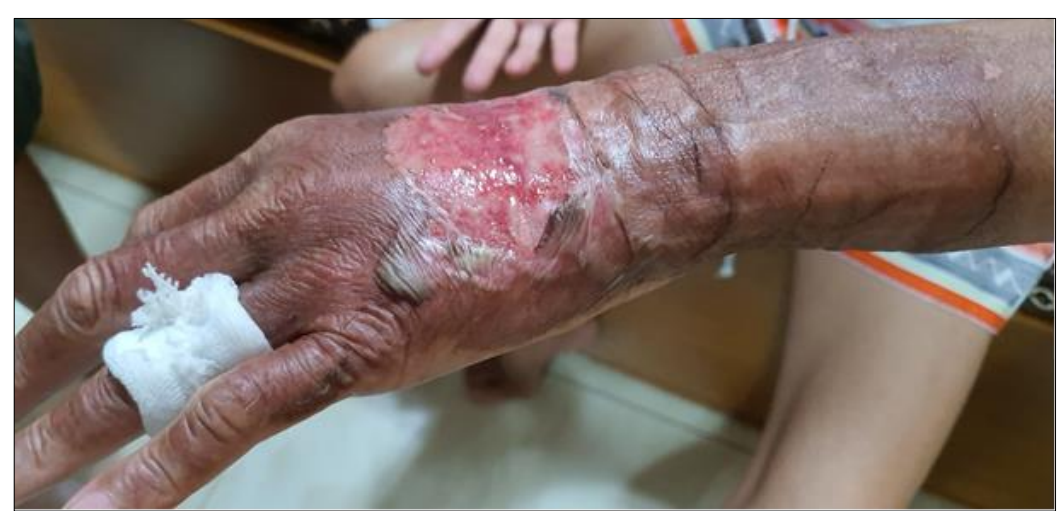

Fig 1: The erythema wound with a plaque size $(6 \mathrm{~cm} \times 3 \mathrm{~cm})$ accompanied by a solitary amount of wet exudate around the wound on the first day of therapy 


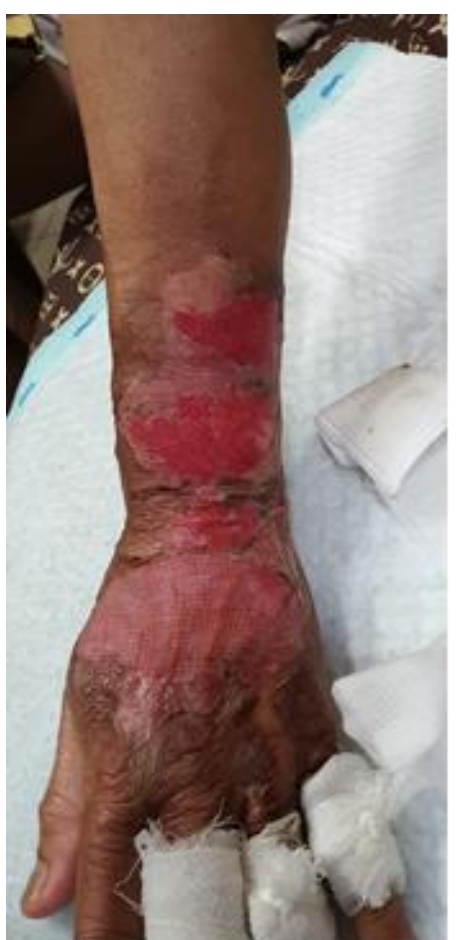

Fig 2: Burns that looked dry on the fifth day

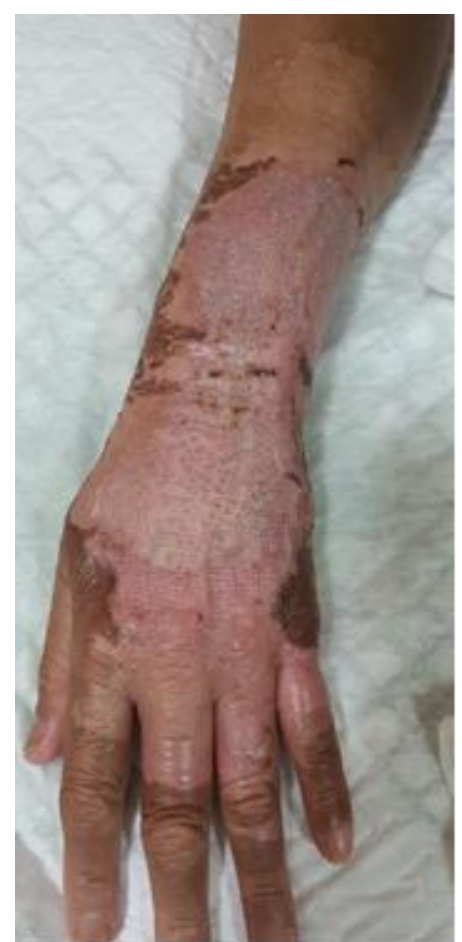

Fig 3: Epithelialization of skin on burns on the fourteenth day

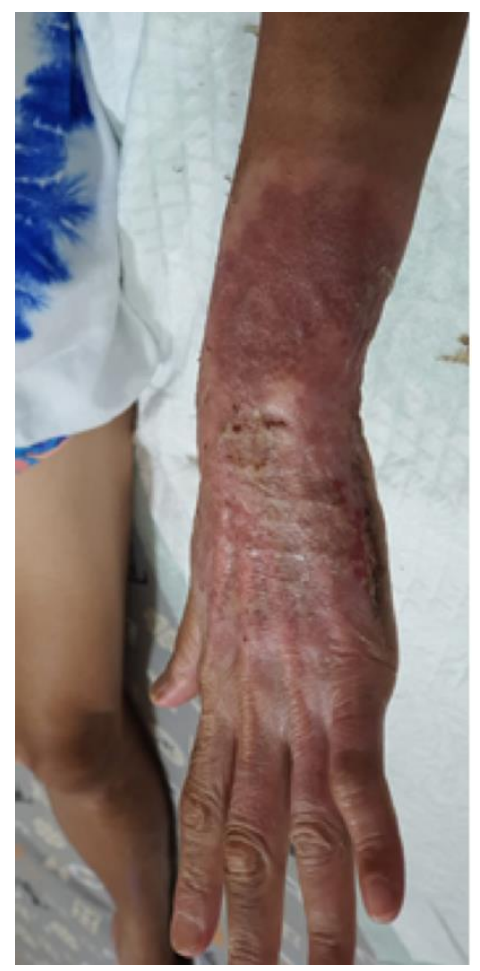

Fig 4: Healing of the burn lesions on the twentieth day

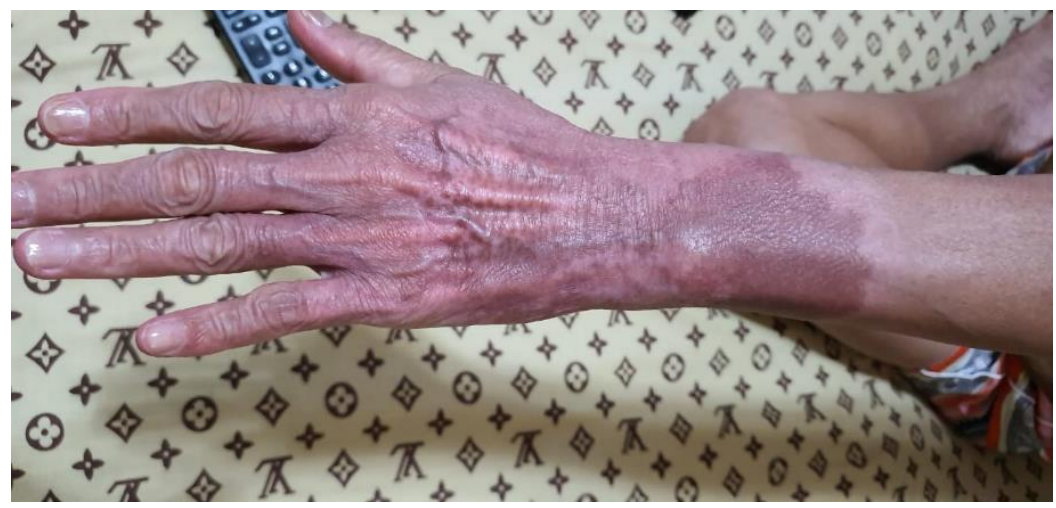

Fig 5: Complete healing on the fourth day

\section{Discussion}

After an acute injury to the skin, the healing mechanism occurs through linear deposition of collagen, which generally does not have the flexibility of the skin as well as normal (unscathed) skin. Although in some methods, wound healing can be produced without a scar, in general, burns almost always cause scars with quite an obvious discoloration. The process of excessive collagen deposition in the wound area can produce pathological wounds that are thick, not flexible, itchy, and often painful ${ }^{[15]}$. There are two forms of pathology due to collagen deposition in post-burn wound areas such as keloids and hypertrophic wounds with different mechanisms of occurrence. ${ }^{(16-19)}$ Although the difference between hypertrophic and keloid scars is not always clear, in general, hypertrophic scars do not exceed the wound margin and do not recurrent after excision. In contrast, keloids often grow beyond the wound margin and persist for a very long time caused disability, aesthetic disturbances, even worse contractures. Several studies have also revealed that patients with burns and dark pigments are prone to developing keloids later in life ${ }^{[19,20]}$.

Wound healing that occurs in three phases includes the phases of inflammation, proliferation, and remodeling ${ }^{[21]}$.
Important things happen during this phase to determine whether a wound will heal without scarring or heal with excess fibrosis. During the inflammatory phase, a fibrin clot will form to trigger the repair process accompanied by the release of cytokines and chemokines, including transforming growth factor- $\beta$, platelet-derived growth factor, insulin-like growth factor, epidermal growth factor, and recruits macrophages, fibroblasts, mast cells, and other cells $[19,21]$. After a few days, the inflammatory phase switches to a proliferative phase, which lasts six weeks. In the case of burns, there is a release of fibroblasts in the dermal tissue, which is a type of fibroblast that is larger, proliferates more slowly, with the result of more collagen and inflammatory cytokines (including TGF- $\beta$ ), and less collagenase enzyme synthesis that triggers a reduction collagen degradation. This whole process activates fibroblasts, which play a role in extracellular matrix synthesis (ECM) with a composition in the form of proteoglycans, hyaluronic acid, procollagen, and elastin, which act as cell modulation and trigger vascularization. From the bone marrow, fibrocytes will migrate to the wound area, and differentiate into fibroblasts, by increasing local TGF- $\beta$ production, stimulating the differentiation of 
fibroblasts into myofibroblasts. Myofibroblasts play a role in reducing the size of the wound. After six weeks, the proliferation phase of the wound will enter the next phase in the form of a remodeling phase with a span of up to 24 months ${ }^{[22]}$.

The optimal wound healing process starts with degraded ECM, and immature type III collagen in the wound is modified to become mature collagen type I, which plays a role in wound healing ${ }^{[22]}$. The characteristic of hypertrophic scars is that there is a disruption in the balance between collagen production and the collagen degradation process. This dysregulation will have an impact on the irregular collagen arrangement characterized by high levels of immature type III collagen, and at least type I mature collagen. Fibronectin and hyaluronic acid synthesis also increase with a decrease in decorin production. The elastin contained in the ECM allows the skin to return to its standard shape after stretching. Clinically, hypertrophic wounds disappear within five years. Changes in the ECM will affect the healing process and the height of the hypertrophic wound ${ }^{[23]}$.

T-helper cells $(\mathrm{CD} 4+)$ influence the phenotypic expression of anti-fibrosis or pro-fibrosis in acute wound injury. Increased collagenase activity occurs as a representative of the anti-fibrotic Type 1 helper $\mathrm{T}$ cell phenotype, which then triggers CD4 + to produce IFN-gamma, IL-2, and IL-12. The phenotype enhancement of pro-fibrosis expression was influenced by Types 2 and 3 helper cell phenotypes expressing IL-2 / IL-5 / IL-10 or TGF- $\beta^{[15]}$.

The explanation of modulation and the pathophysiology of wound healing above can be overcome by giving stem cells, which are hypothesized to have superior effectiveness when compared to conventional therapy in terms of reducing the incidence of burn complications in the form of hypertrophic and keloid wounds (Figure. 6). The use of stem cell therapy is a discovery that can be likened to a gold mine in any treatment of various diseases. Several studies using stem cells have been conducted with astonishing results in areas ranging from oncological and hematological diseases to organ transplantation to wound healing ${ }^{[24-26]}$.

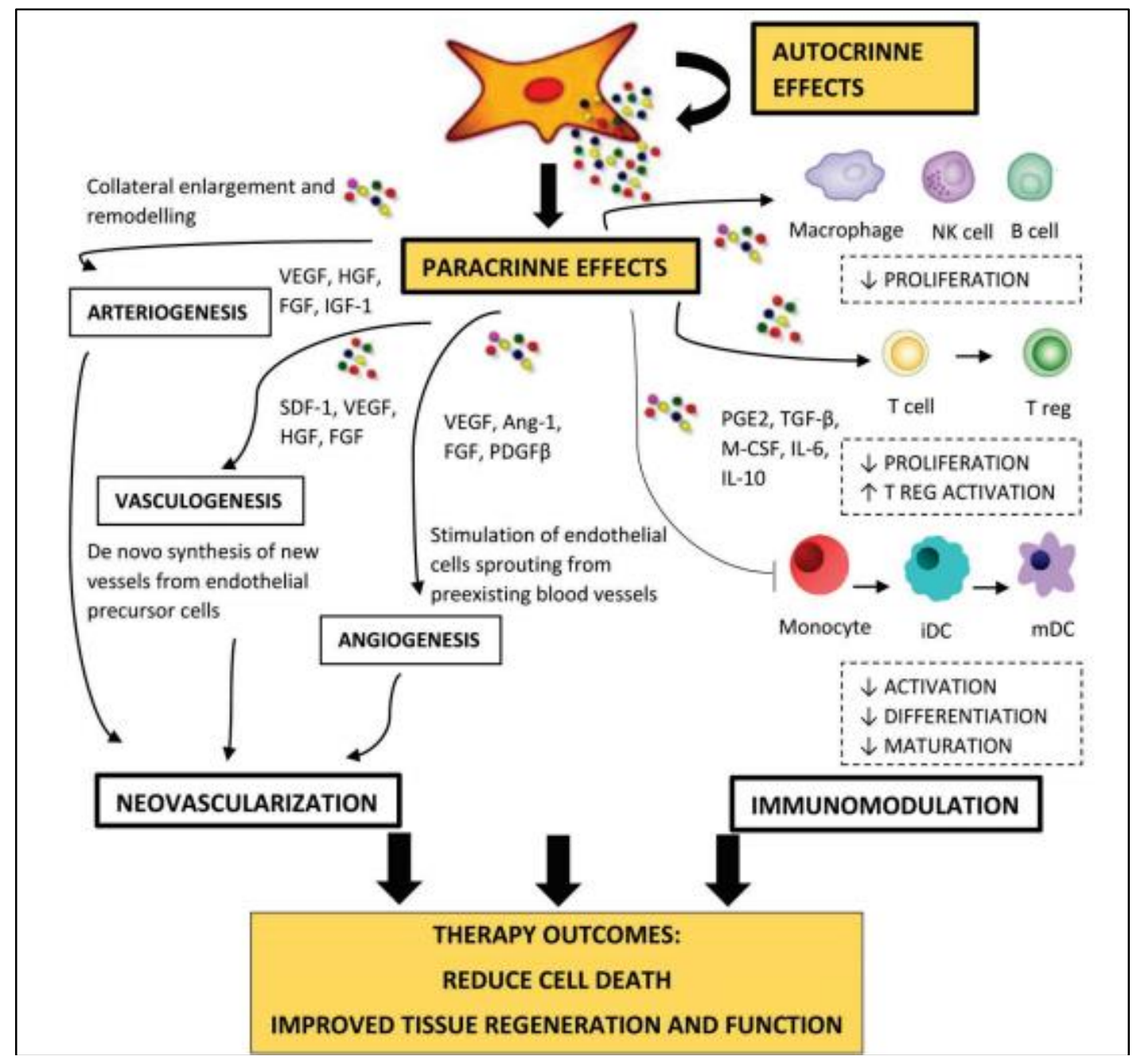

Fig 5: Mechanisms of Immodulation and Neovascularization in the use of stem cell therapy ${ }^{(27)}$

Generally, stem cells are defined as undifferentiated cells with the ability to self-regenerate through replication into more specific cells ${ }^{[28]}$. Stem cells are not only specific but also act as stem cells, which are called progenitors or precursors ${ }^{[29]}$. To date, there has been increasing use of mesenchymal stem cells (MSC) in various types of applications due to the multipotent characteristics of MSCs. Several studies have shown that stem cells derived from bone marrow (BM-SC) can act as precursors that develop from the germ layer pathway to various cell types such as adipose, chondrocytes, and solid osteocytes [30]. BM-SC contains Vascular Endothelial Growth Factor (VEGF) or Fibroblast Growth Factor (FGF), which is necessary for wound healing ${ }^{[31]}$. VEGF is an essential component for maintaining hypoxic tissue ${ }^{[32]}$. The case report from Sarasua et al. stated that there was wound closure 18 days after BM- 
SC injection of stage IV pressure ulcer ${ }^{[33]}$.

Research by Shumakov et al. is the first study to use stem cells derived from mesenchymal bone marrow (BMSC) to heal burns in mice and with a comparative control in the form of embryonic fibroblasts. The intervention used was mesenchymal bone cells that were processed in the form of a gel and applied to the wound area. The results of this study showed that the granulation tissue was better than the control ${ }^{[34]}$. Research by Chunmeng et al. found that topical systemic dermis transplantation containing many multipotent cells promoted radiation-induced wound healing in mice that were more superior to controls without transplantation ${ }^{[35]}$.

Rasulov et al. Initiated the use of stem cells extracted from mesenchymal bone marrow in a female patient with extensive skin burns (IIIB 30\% of body surface area). Stem cells are applied topically to the burn surface. The final results of this study indicate that the use of stem cells promotes faster wound healing with better quality and triggers active neoangiogenesis ${ }^{[36]}$.

Research on topical stem cell administration was continued by Lataillade et al., who reported two cases in which stem cells were used as adjunctive therapy to aid burn healing. Mesenchymal stem cells are applied, after surgical action, flaps, and grafts, to radiation burns. The results of this study revealed that the level of inflammation in patients on stem cell therapy was lower as well as higher cure rates and shorter healing times ${ }^{[37,38]}$.

Data from animal models have shown that the autocrine or paracrine effects of MSCs have played a key role in wound healing ${ }^{[31]}$. Several studies have reported the presence of growth factors in MSC-CM contributes to the regeneration of damaged organ tissues. It is also worth mentioning that the secretomes of MSCs have anti-fibrotic and angiogenic effects, which can reduce scar tissue formation when given early ${ }^{[39]}$.

This case report shows that using 10\% topical Gel of Secretom from Placenta Warton Jelly Mesenchymal Stem Cell (SC-PWJSC) therapy is an effortless way and can even be applied independently by patients with favorable outcomes and reducing future disability. In this case, hyperpigmentation is still one of the challenging problems in burn wound management. We hope, in the future this research can be carried out on a large scale in Indonesia starting from serial case reports, clinical trials, to Randomized Controlled Trial (RCT).

\section{Conclusion}

Burns are a form of injury to the skin, or other tissues, caused by heat, cold, electricity, chemicals, friction, or radiation with a high incidence and a significant impact because they often cause hypertrophic scars, keloids, aesthetic disturbance, the worst is contracture that caused disability on limbs area. Reported one case of $2^{\text {nd }}$ degree burns of the left dorsum manus area in a woman aged 47 years. Therapy using $10 \%$ topical Gel of Secretom from Placenta Warton Jelly Mesenchymal Stem Cell (SCPWJSC) for 3 weeks, oral antibiotic, analgetic and vitamin C showed very satisfactory results with no scar, no hypertrophic scar or keloid in $2^{\text {nd }}$ degree of burn on moving area, finding none of any significant side effects locally or systemic, still, hyperpigmentation remains.

\section{References}

1. Herndon DN. Total burn care. Total Burn Care: Fourth Edition, 2012.

2. WHO. WHO|Burns. Who, 2018.

3. World Health Organization. Burns, Fact sheet $N^{\circ} 365$, 2014.

4. Gibran NS, Wiechman S, Meyer W, Edelman L, Fauerbach J, Gibbons L, et al. American Burn Association Consensus Statements. J Burn Care Res, 2013.

5. American Burn Association. Burn Incidence and Treatment in the United States: 2016. Burn Incidence Fact Sheet, 2016.

6. Association AB. Burn Incidence and Treatment in the United States: 2013 Fact Sheet. American Burn Association National Burn Repositorym, 2013.

7. Mann R, Heimbach D. Prognosis and treatment of burns. In: Western Journal of Medicine, 1996.

8. Bombaro KM, Engrav LH, Carrougher GJ, Wiechman SA, Faucher L, Costa BA, et al. What is the prevalence of hypertrophic scarring following burns? Burns [Internet]. 2003; 29(4):299-302. Available from: http://www.ncbi.nlm.nih.gov/pubmed/12781605

9. Finnerty CC, Jeschke MG, Branski LK, Barret JP, Dziewulski P, Herndon DN. Hypertrophic scarring: the greatest unmet challenge after burn injury. Lancet (London, England) [Internet]. 2016; 388(10052):1427$36 . \quad$ Available from: http://www.ncbi.nlm.nih.gov/pubmed/27707499

10. Ahuja RB, Puri V, Gibran N, Greenhalgh D, Jeng J, Mackie D, et al. ISBI Practice Guidelines for Burn Care. Burns, 2016.

11. Endorf FW, Ahrenholz D. Burn management. Current Opinion in Critical Care, 2011.

12. Wang Y, Beekman J, Hew J, Jackson S, Issler-Fisher AC, Parungao $\mathrm{R}$ et al. Burn injury: Challenges and advances in burn wound healing, infection, pain and scarring. Advanced Drug Delivery Reviews, 2018.

13. Johnson C. Management of burns. Surgery (United Kingdom), 2018.

14. Snell JA, Loh NHW, Mahambrey T, Shokrollahi K. Clinical review: The critical care management of the burn patient. Critical Care, 2013.

15. Tredget EE, Levi B, Donelan MB. Biology and principles of scar management and burn reconstruction. Surg Clin North Am [Internet]. 2014; 94(4):793-815. Available from: http://www.ncbi.nlm.nih.gov/pubmed/25085089

16. Patel PA, Bailey JK, Yakuboff KP. Treatment outcomes for keloid scar management in the pediatric burn population. Burns [Internet]. 2012; 38(5):767-71. Available from: https://linkinghub.elsevier.com/retrieve/pii/S030541791 1003457

17. Arno AI, Gauglitz GG, Barret JP, Jeschke MG. Up-todate approach to manage keloids and hypertrophic scars: A useful guide. Burns [Internet]. 2014; 40(7):1255-66. Available from: https://linkinghub.elsevier.com/retrieve/pii/S030541791 4000710

18. Ogawa R. The most current algorithms for the treatment and prevention of hypertrophic scars and keloids. Plast Reconstr Surg [Internet]. 2010; 125(2):557-68. 
Available

from: http://www.ncbi.nlm.nih.gov/pubmed/20124841

19. Niessen FB, Spauwen PH, Schalkwijk J, Kon M. On the nature of hypertrophic scars and keloids: a review. Plast Reconstr Surg [Internet]. 1999; 104(5):1435-58. Available from: http://www.ncbi.nlm.nih.gov/pubmed/10513931

20. Gauglitz GG, Korting HC, Pavicic T, Ruzicka T, Jeschke MG. Hypertrophic Scarring and Keloids: Pathomechanisms and Current and Emerging Treatment Strategies. Mol Med [Internet]. 2011; 17(1-2):113-25. Available from: https://molmed.biomedcentral.com/articles $/ 10.2119 / \mathrm{mol}$ med.2009.00153

21. Tredget EE, Nedelec B, Scott PG, Ghahary A. HYPERTROPHIC SCARS, KELOIDS, AND CONTRACTURES. Surg Clin North Am [Internet]. 1997; 77(3):701-30. Available from: https://linkinghub.elsevier.com/retrieve/pii/S003961090 5705764

22. Slemp AE, Kirschner RE. Keloids and scars: a review of keloids and scars, their pathogenesis, risk factors, and management. Curr Opin Pediatr [Internet]. 2006; 18(4):396-402. Available from: http://journals.lww.com/00008480-200608000-00011

23. Oliveira GV, Hawkins HK, Chinkes D, Burke A, Tavares ALP, Ramos-e-Silva M, et al. Hypertrophic versus non hypertrophic scars compared by immunohistochemistry and laser confocal microscopy: type I and III collagens. Int Wound J [Internet]. 2009; 6(6):445-52. Available from: http://doi.wiley.com/10.1111/j.1742481X.2009.00638.x

24. Kucharzewski M, Rojczyk E, Wilemska-Kucharzewska $\mathrm{K}$, Wilk R, Hudecki J, Los MJ. Novel trends in application of stem cells in skin wound healing. European Journal of Pharmacologym, 2019.

25. Jayaraman $P$, Nathan $P$, Vasanthan $P$, Musa $S$, Govindasamy V. Stem cells conditioned medium: A new approach to skin wound healing management. Cell Biol Int, 2013.

26. P. J, P. N, P. V, S. M, V. G. Stem cells conditioned medium: A new approach to skin wound healing management. Cell Biology International, 2013.

27. Samakova A, Gazova A, Sabova N, Valaskova S, Jurikova M, Kyselovic J. The pi3k/Akt pathway is associated with angiogenesis, oxidative stress and survival of mesenchymal stem cells in pathophysiologic condition in ischemia. Physiol Res, 2019.

28. Pawitan JA. Prospect of stem cell conditioned medium in regenerative medicine. BioMed Research International, 2014.

29. Li CY, Wu XY, Tong JB, Yang XX, Zhao JL, Zheng QF et al. Comparative analysis of human mesenchymal stem cells from bone marrow and adipose tissue under xeno-free conditions for cell therapy. Stem Cell Res Ther, 2015.

30. Singh R, Singh R, Rohilla RK, Siwach R, Verma V, Kaur K. Surgery for pressure ulcers improves general health and quality of life in patients with spinal cord injury. J Spinal Cord Med, 2010.

31. Utomo W, Dewi YI, Abdurrasyid T. Efektifitas Nigella Sativa Oil Untuk Mencegah Terjadinya Ulkus
Dekubitus Pada Pasien Tirah Baring Lama. J Ners Indones. 2014; 2(2):151-7.

32. Yolanda M-M. Adult Stem Cell Therapy in Chronic Wound Healing. J Stem Cell Res Ther, 2014.

33. González Sarasúa J, Pérez López S, Álvarez Viejo M, Pérez Basterrechea M, Fernández Rodríguez A, Ferrero Gutiérrez A, et al. Treatment of pressure ulcers with autologous bone marrow nuclear cells in patients with spinal cord injury. J Spinal Cord Med, 2011.

34. Shumakov VI, Onishchenko NA, Rasulov MF, Krasheninnikov ME, Zaidenov VA. Mesenchymal bone marrow stem cells more effectively stimulate regeneration of deep burn wounds than embryonic fibroblasts. Bull Exp Biol Med, 2003.

35. Chunmeng S, Tianmin C, Yongping S, Xinze R, Yue M, Jifu Q, et al. Effects of dermal multipotent cell transplantation on skin wound healing. J Surg Res, 2004.

36. Rasulov MF, Vasil'chenkov A V., Onishchenko NA, Krasheninnikov ME, Kravchenko VI, Gorshenin TL, et al. First experience of the use bone marrow mesenchymal stem cells for the treatment of a patient with deep skin burns. Bull Exp Biol Med, 2005.

37. Lataillade JJ, Doucet C, Bey E, Carsin H, Huet C, Clairand I, et al. New approach to radiation burn treatment by dosimetry-guided surgery combined with autologous mesenchymal stem cell therapy. Regen Med, 2007.

38. Bey E, Prat M, Duhamel P, Benderitter M, Brachet M, Trompier $\mathrm{F}$, et al. Emerging therapy for improving wound repair of severe radiation burns using local bone marrow-derived stem cell administrations. Wound Repair Regen, 2010.

39. Vizoso FJ, Eiro N, Cid S, Schneider J, Perez-Fernandez R. Mesenchymal stem cell secretome: Toward cell-free therapeutic strategies in regenerative medicine. International Journal of Molecular Sciences, 2017. 